\title{
Multimedia Instructional Message (MIM) and Simulation-Aided Learning: A Conceptual Framework
}

\author{
Mohd Syahrizad Elias and Ahmad Zamzuri Mohamad Ali
}

\begin{abstract}
Simulation-aided learning has the ability to attract the attention and interest of students to learn. However, the effectiveness of simulation-aided learning requires adequate instructional support to sufficiently achieve the learning objectives. Multimedia Instructional Message (MIM) serves as an instructional support in building this meaningful learning, especially in helping the exploration of complex simulation application, abstract learning content delivery and delivery of learning that requires a combination of skills. Effective MIM strategy depends on the selection of images and the medium of communication used in the delivery of teaching and learning strategies. The effectiveness of the image depends on the form of the graphics used either printed static graphics, digital static graphics or animated digital graphics apart from other factors such as learning styles and students' prior knowledge. Taking these into consideration, this paper proposes a conceptual framework for research related to simulation-aided learning.
\end{abstract}

Index Terms - Animation, graphics, instructional, learning style, multimedia instructional message (MIM), simulation.

\section{INTRODUCTION}

Simulation has potential in delivering learning content sufficiently in the teaching and learning process [1] and at present, it can be applied in various aspects and educational field [2]. Simulation has the ability to involve interaction with learning contents in a virtual situation or in actual condition [2], [3]. It is also known as a program that is designed to model a phenomenon or activity that allows a student to interact with the program and usually the student has an active role in exploring it [4]. Some of the interesting characteristics of simulation are its ability to integrate various media such as text, pictures, audio, animation and video, and subsequently produce an aid for delivering learning contents that are capable of attracting the student's attention [5].

However, there are simulations with complex features that might increase the challenges for students in exploring it, in which they need a proper training to ensure the maximum impact of learning [6]. The effectiveness of the simulation actually depends on the instructional support and guide on how the student should explore it [4]. This instructional support is also known as the Multimedia Instructional Message (MIM) [7]. Students need assistance, such as the MIM, as a guide or work measure to use complex simulations

Manuscript received November 20, 2014; revised March 6, 2015.

Mohd Syahrizad Elias is with Politeknik Seberang Perai, Jalan Permatang Pauh, 13500 Seberang Perai, Pulau Pinang, Malaysia (e-mail: syahrizad79@yahoo.com).

Ahmad Zamzuri Mohamad Ali is with the Faculty of Art, Computing and Creative Industry, Universiti Pendidikan Sultan Idris, 35900 Tanjong Malim Perak, Malaysia (e-mail: zamzuri@fskik.upsi.edu.my). correctly and effectively. MIM is the main and important element, which is the guide for multimedia based learning [8]. It is a mode of communication that integrate visual and verbal information with the intention to improve learning [8], [9]. This type of communication can be delivered through any form of media, including printed media such as books, or the digital media such as computers. The words can be in the form of printed text or in verbatim, while images can be static images such as illustrations and photos or dynamic images such as animations and video clips [8]. Fig. 1 gives a visual depiction of the MIM framework as adapted from Mayer and Moreno [8].

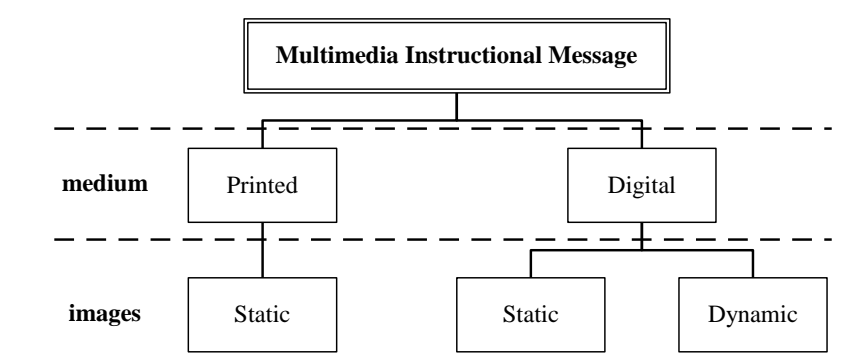

Fig. 1. The Multimedia instructional message (MIM) adapted from Mayer and Moreno [8].

Although MIM is capable in supporting instruction for simulation-aided learning, the question arises whether the MIM delivery strategy prepared by the simulation developer can actually contribute to effective learning. This issue needs to be emphasized as delivery strategy, which is not in accordance with the students learning needs, will reduce the effectiveness of an instructional material [9]. Effective learning will only happens if delivery is aided by adequate instructional material with the exact and effective strategies [10]. Therefore, research on the MIM delivery strategy that looks into various aspects including the delivery strategy and learning style is crucial in promoting meaningful knowledge forming process [11], [12].

\section{StATIC IMAGE OR DYNAMIC IMAGE?}

MIM approach can be delivered through printed or digital media. The MIM in digital media can be delivered in either static or dynamic form. Apparently, most teachers have the belief that static image is a passive medium and is not the right choice compared to animation, which is an active medium [13]. Hence, research had revealed that dynamic images are not permanently effective compared to the series of static images when depicting the same contents. A research by Mayer, Hegarty, Mayer and Campbell [14], found that static images in the instructional material were more effective compared to dynamic images. In their research, two MIM 
methods were used to depict the concept of storms and lightning formation. The first method used the printed media delivery, which is a series of static images with textual explanations, whereas the second method used dynamic images with verbal explanations. The research findings showed that the first method, which used the printed media with a series of static images, was better compared to dynamic images in animated form.

The same results were obtained in a few other research including learning related to the formation of waves, hydraulic pump concept and function of septic tank, which also showed the delivery in the form of static images was more effective compared to dynamic images in the form of animated instructions [13]. Nevertheless, the research findings above are actually limited to learning contents that depict a particular process. There are also researches that show dynamic images in the form of animation to be more effective for learning, especially learning that involves work procedures. For example, a research to determine the effectiveness of teaching related to making paper flowers and hats found that dynamic images in the form of animation were more effective than static images [15]. The same results were seen in a research carried out to determine the effectiveness of teaching related to making neckties and puzzle rings [15].

In conclusion, the findings from the researches above show that the static images are suitable for depicting a process, while the dynamic images are suitable for depicting work procedures or practical work. Hence, this raises the question, "what about the MIM strategy, which is suitable for simulation based learning that requires the students to understand processes and procedures that involves application of complex theories and concepts in solving a particular task or problem, such as programming and configuration of networking equipment"? Therefore, should MIM in the form of static images, either printed or digital, or dynamic images in animated form should be used?

The research discussed above indicates that static images are suitable for developing knowledge related to depicting a process whereas dynamic images in animation form are suitable for teaching practical skills. Yet, these researches are actually limited to contents that are not abstract and practical skills that are psychomotor in nature. For simulation based learning that involves abstract content, the developed MIM needs to be able to depict procedures of using the simulation, build theoretical skills such as understanding configuration and visualize the process based on the configuration. It is important that the research is conducted to determine the MIM strategy that is most suitable to build all the three skills stated above simultaneously in simulation based learning. This issue is important to be addressed as much research that have been done focused primarily on building only one particular skill and not a combination of numerous skills.

\section{PRIOR KNOWLEDGE}

Besides, the aspect of learning content as discussed above, prior knowledge is among the factors that influence the effectiveness of learning contents in visual form regardless of whether the delivery uses static or dynamic images [16]-[18]. The difference in the level of prior knowledge may not only influence the processing of received visual information [18], but also influence the perception, attention span and delivery of subsequent learning content [19].

Prior knowledge is related information owned by students before they are exposed to specific learning domains [20]. Prior knowledge can be divided into low prior knowledge if the student has little knowledge and high prior knowledge if the student has a lot of prior knowledge related to the content to be learned [21]. However, Mayer and Sims [21] did not specifically explain how the student's low and high level of prior knowledge was determined. However, based on the previous research, low prior knowledge can be categorized as a student who has never been exposed to related learning domain or known as a novice student [20]. Meanwhile, students with high prior knowledge are categorized as students who have been exposed to related learning domain and are known as well-learned or experienced students [20].

The effectiveness of MIM strategy on novice students may not be similar compared to well-learned or experienced students [22], [23]. This can be seen in the research on learning of content about probability involving novice students who received five different versions of delivery; text, static visual, static motion cues, computer animated and interactive animation [24]. The findings from the above study showed that students who received delivery of learning contents in the form of static and animated form managed to solve the problem given more accurately compared to the group that received delivery of learning contents only in the text form [24]. However, the novice students who received the delivery based on the dynamic images in animated form managed to solve the problem more accurately compared to the novice students who received the delivery based on static images and text [24]. Dynamic images in an animated form in particular situations are more effective compared to the delivery by static images in encouraging learning. However, in most situations, the added advantage of delivery by dynamic images in animated form is modest compared to static images because dynamic image delivery in animated form is used on knowledgeable students [25]. The dynamic image delivery in animated form can be effectively used based on two factors; dynamic images in animated form in delivering learning contents that need a particular solution or delivery in the form of practical skills, and the delivery is limited to novice students only [15], [24]. Hence, this leads to the question "what about the static image delivery in the learning and teaching process"? Will the static image delivery depend on the same factor as the dynamic image delivery in animated form?

Besides the research above, Mayer and Sim [21] had conducted research on different forms of learning content deliveries such as learning in descriptive and procedural forms on novice and knowledgeable students. Both these forms of learning contents were delivered with the assistance of static and dynamic images in animated form. According to [26], the descriptive learning content is knowledge in the form of elucidation or explanation and is known as 'knowing that', while learning content in the procedural form or learning how to explain a particular process is known as 'knowing how'. The results of the research showed that both forms of learning contents that used static images affect novice students 
significantly [20]. Meanwhile, knowledgeable students did not show any effect when they received learning delivery aided by either static images or dynamic images in animated form [20]. Also, based on this research, there were signs of significant interaction between the form of delivery and the level of inherent knowledge among students in both groups. This shows that different visual deliveries need to be used for different levels of prior knowledge among students. Overall, the research by ChanLin [20] had found that using static images was more effective than using text for descriptive learning contents and more effective than text and animation for procedural learning contents among novice students. On the other hand, for knowledgeable students, there were no significant differences for all the delivery strategies. The findings of ChanLin [20] seem are not consistent with that of Kaplan and $\mathrm{Wu}$ [24]. Besides the prior knowledge, the learning content factor might also influence the difference in findings for novice students in both research studies. In relation to that, further research is important to determine the effect of prior knowledge on the MIM's strategy for abstract simulation based learning contents.

\section{LEARNING STYLES}

Use Besides the prior knowledge factor, the MIM strategy also has an effect on students' learning styles [11], [27]. The students learning style is also the main factor in the 'meaningful knowledge' formation [11], [12]. Hence, research related to MIM strategy should not be limited to the delivering strategy but should also look into the aspects of learning styles. Learning styles can be defined as how a student pays attention, processes and maintains information while learning [28]. Learning styles have a few levels of tendencies [29], and these tendencies are evaluated based on the learning levels of a student, whether it is high, medium or low [30]. Hence, the development of instructional material needs to commensurate with the tendency to ensure maximum learning effectiveness [31], [32]. The learning style needs to be suitable and befitting the related field of study or needs of a study course because it will have an effect on student's achievements [33], [34].

\section{THEORETICAL FRAMEWORK}

The theoretical framework for this research is grounded on two main references; the Mayer Cognitive Theory of Multimedia Learning [7] and Felder-Silverman Model of Learning Styles (FSMLS) [27].

The Mayer Cognitive Theory of Multimedia Learning contains three main principles as outlined by Mayer [7], [9] and are stated as follows:

1) Information enters through two channels. Each individual receives information on learning contents through two channels, which are through verbal channel and visual channel.

2) Limited capacity. Each individual has limitations in processing information in each channel at one time.

3) Assume the processing is active. Everyone has an active relationship in the cognitive process. This is to build a coherent mental model with information that is received and the prior knowledge the individual has.

The relationship between the three principles starts with the input of information from the two channels, namely the ears, which receive verbal information and the eyes which receive visual information. Both these channels will go through three cognitive processes. The first cognitive process starts when the chosen verbal information is taken to be processed in the verbal working memory, while the chosen visual information is taken to be processed in the visual working memory. The second cognitive process involves organizing the verbal information received into the verbal mental model, and the visual information received into the visual model. However, the working memory has limited receiving and processing capacity. This limitation will influence the effectiveness of the learning process [35]. The last cognitive process involves integrating the verbal and visual mental models together with the prior knowledge of the student. This integration will result in new knowledge construction and will be kept in the long-term memory of the student in schema form.

However, the effectiveness of multimedia presentation is limited due to the limited capacity of cognitive process in the verbal or visual channels of an individual [36], [37]. This limitation will have an effect on learning, especially when students fail to build complete verbal and visual mental models in the working memory. Exploring complex simulation applications, together with numerous applications of abstract concepts and without guidance that supports correct instructions, would eventually increase the level of cognitive burden and disrupt the building of meaningful learning [35]. MIM is seen as a medium of communication that is useful in managing cognitive burden and stimulates the learning environment better. This is because effective learning will only occur if the delivery assisted by instructional material is used with the correct and effective strategy [10].

Critical thinking, problem solving skills and applying a concept will surely increase the burden of working memory [35] while building the mental model that will be integrated with prior knowledge. Vision is an active element in the teaching and learning process [38]. An active cognitive process in the working memory of an individual that is building meaningful learning will facilitate that process. However, the effectiveness of using visuals depends on the level of tendency of the student's learning styles [38], [39].

The expertise reversal effect is among the factors that need to be considered when developing instructions aided by static or dynamic images. Using images or instructional designs for novice students may be effective but not for knowledgeable students, as it could bring negative understanding towards the learning contents that are being delivered or known as "expertise reversal effect" [35], [40]-[42]. Hence, a specific evaluation is needed to ascertain whether the student receiving MIM strategy is a novice or knowledgeable student.

Felder-Silverman Model of Learning Styles (FSMLS) [27], classify and describe the learning style of a learner in more details based on four specific dimensions and described in Table I. 
TABLE I: FELDER-SILVERMAN LEARNING STYLE MODEL DIMENSION [43]

Dimension

1. Active-Reflective

2. Sensory-Intuitive

3. Visual-Verbal

4. Sequential-Global

Active learner will actively used the aided learning material, colaborative learning, learn by trying out. Reflective learner will learn by thinking through, prefer in work alone or with a single partner

Sensory learner thinking towards fact, concrete thinker, practical and stick with the procedure

Intuitive learner is abstract thinker, creative, innovative and survey all the circumtances in problem solving.

Visual learner prefer the visual representations of presented material, such as pictures, images, diagrams and flow charts.

Verbal learner prefer spoken and written explanation.

Sequential learner prefer learn in a small incremental steps, linear thinking process.

Global learner learn in a holistic thinking process, learner are able to learn in a random, learn in a large steps leap.

However, the conceptual framework of this research only focuses on the visual learning styles. This is due to the initial survey findings that nearly 94 percent of technical students tend to visual learning style [44]. The study showed that the use of visual elements is preferred element by students. However, the question arises, whether static visual or dynamic visual that should be an option? It is important to find a solution, particularly for the abstract content presentation which involves various learning skills.

\section{CONCEPTUAL FRAMEWORK}

Based on the theoretical framework and the literature overview, the conceptual framework was developed as shown in Fig. 2 below:

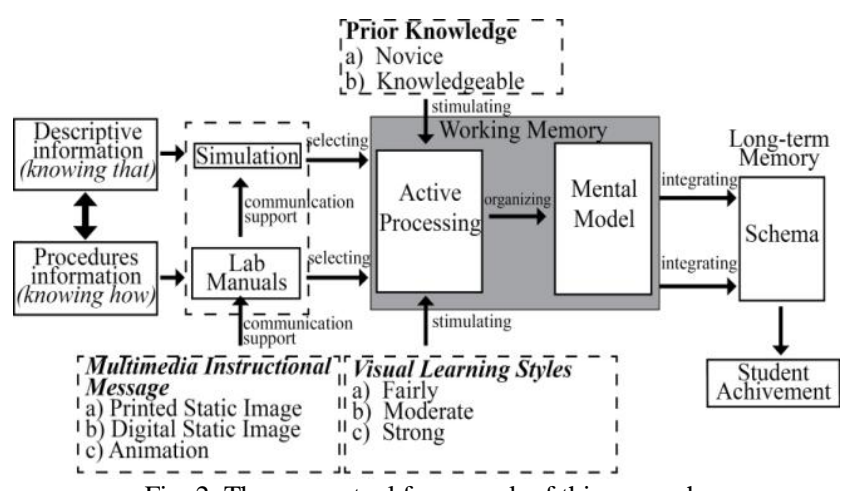

Fig. 2. The conceptual framework of this research.

The three key words to describe the cognitive process are select, organize and integrate. Before the selection of information happens, MIM plays an influence communication support role throughout the exploration of complex simulation in learning process. Complex simulation alone in improving learning outcomes will burden the memory management; in this situation the successfulness of selecting information to be processed in memory structure will be hindered. Successful information selection will occur if the descriptive information and procedures information established through the simulation learning activities are sustained with MIM. Simulation learning complemented with MIM in the form of laboratory worksheets will act as a communication support in the learning process. However, question arises, which MIM strategy is regarded helpful for effective simulation learning; either printed static images, digital static images or animation? The selection of appropriate MIM strategy will attribute to noteworthy impact on students' achievement. The selection of appropriate MIM strategies requires researches which focus on its effect on student achievement, particularly in developing multiple skills. Therefore, the conceptual framework requires further research to address this question before finalization. Beside the study on effects of various MIM strategies, study on the impact and influence of prior knowledge and learning style is also crucial to affirm the conceptual framework.

\section{CONCLUSION}

Simulation has the ability to attract the attention and interest of students to learn. However, the effectiveness of simulation depends critically on the active learning condition applied; such as simulation with laboratory worksheets, simulation with games, and simulation in problem-based learning. Effective simulation learning needs instructional material support in order to achieve the learning objectives successfully. The role of MIM which guide the exploration of complex simulations, deliver the abstract learning contents and delivery that needs the combination of various skills; has potential in promoting meaningful learning. However, studies are needed in determining the best MIM strategy for simulation learning, specifically for students with different learning styles and level of prior knowledge.

\section{REFERENCES}

[1] G. K. Akilli, "Games and simulations: A new approach in education?" in Games and Simulations in Online Learning: Research and Development Frameworks, D. Gibson, C. Aldrich, and M. Prensky, Eds., Hershey: Idea Group Inc, 2007, pp. 1-20.

[2] K. Barton and P. Maharg, "E-simulations in the wild: Interdisciplinary research, design and implementation," in Games and Simulations in Online Learning: Research and Development Frameworks, D. Gibson, C. Aldrich, and M. Prensky, Eds., Hershey: Idea Group Inc, 2007, pp. $115-148$.

[3] Y. Baek, "Digital simulation in teaching and learning," in Digital Simulations for Improving Education: Learning Through Artificial Teaching Environments, D. Gibson and Y. Baek, Eds., Information Science References, 2009, pp. 25-51.

[4] L. P. Rieber, "Multimedia learning in games, simulations and microworlds," in The Cambridge Handbook of Multimedia Learning, R. E. Mayer, Ed., Cambridge University Press, vol. 16, no. 1998, 2005, pp. 663.

[5] V. N. Kettanurak, K. Ramamurthy, and W. D. Haseman, "User attitude as a mediator of learning performance improvement in an interactive multimedia environment: An empirical investigation of the degree of interactivity and learning styles," Int. J. Hum. Comput. Stud., vol. 54, no. 4, pp. 541-583, 2001.

[6] M. C. Mayrath, "Examining factors that affect performance in complex simulation environments," The University of Texas, 2009.

[7] R. E. Mayer, Multimedia Learning, 2nd Ed., New York: Cambridge University Press, 2009, p. 57.

[8] R. E. Mayer and R. Moreno, "Nine ways to reduce cognitive load in multimedia learning," Educ. Psychol., vol. 38, no. 1, pp. 43-52, 2003.

[9] R. E. Mayer, "Introduction to multimedia learning," in The Cambridge Handbook of Multimedia Learning, R. E. Mayer, Ed., Cambridge University Press, 2005, pp. 1-16.

[10] R. C. Clark, Learning from Media: Arguments, Analysis and Evidence, Greenwich, CT: Information Age Publishers, 2001.

[11] R. M. Felder and R. Brent, "Understanding student differences," J. Eng. Educ., vol. 94, no. 1, pp. 57-72, 2005. 
[12] (2012). Model pembelajaran Gaya Belajar VARK dalam mata pelajaran Teknologi Informasi Dan Komunikasi Berbasis Multimedia Interaktif. Universiti Pendidikan Indonesia. [Online]. Available: http://flashfisika.blogspot.com/2011/10/model-pembelajaran-gaya-be lajar-vark.html

[13] K. K. Jabbour, "Multimedia principle in teaching lessons," Acta Didact. Napocensia, vol. 5, no. 4, Oct. 2012.

[14] R. E. Mayer, M. Hegarty, S. Mayer, and J. Campbell, "When static media promote active learning: Annotated illustrations versus narrated animations in multimedia instruction," J. Exp. Psychol. Appl., vol. 11, no. 4, pp. 256-65, Dec. 2005.

[15] A. Wong, N. Marcus, P. Ayres, L. Smith, G. A. Cooper, F. Paas, and J. Sweller, "Instructional animations can be superior to statics when learning human motor skills," Comput. Hum. Behav., vol. 25, no. 2, pp. 339-347, Jan. 2009.

[16] R. E. Mayer and R. Moreno, "Aids to computer-based multimedia learning," Learn. Instr., vol. 12, no. 1, pp. 107-119, 2002.

[17] R. E. Mayer, "Instruction based on visualizations," in Handbook of Research on Learning and Instruction, R. E. Mayer and P. A. Alexander, Eds., New York: Routledge, 2011, pp. 427-445.

[18] F. Vetere and S. Howard, "Prior knowledge and redundant multimedia," in Proc. IEEE International Conference on Multimedia and Expo, 2000, vol. 2, pp. 605-608.

[19] M. P. Cook, "Visual representations in science education: The influence of prior knowledge and cognitive load theory on instructional design principles," Sci. Educ., vol. 90, no. 6, pp. 1073-1091, Apr. 2006.

[20] L. C. Lin, "Formats and prior knowledge on learning in a computer-based lesson," J. Comput. Learn., vol. 17, pp. 409-419, Jan. 2001.

[21] R. E. Mayer and V. K. Sims, "For whom is a picture worth a thousand words? Extensions of a dual-coding theory of multimedia learning," $J$. Educ. Psychol., vol. 86, no. 3, pp. 389-401, Sep. 1994.

[22] R. Moreno and R. E. Mayer, "Interactive multimodal learning environments special issue on interactive learning environments: Contemporary issues and trends," Educ. Psychol. Rev., vol. 19, no. 3, pp. 309-326, Jun. 2007.

[23] R. Moreno and A. Valdez, "Cognitive load and learning effects of having students organize pictures and words in multimedia environments: The role of student interactivity and feedback," Educ. Technol. Res. Dev., vol. 53, no. 3, pp. 35-45, Sep. 2005.

[24] D. E. Kaplan and E. C. Wu, "Computer-based graphical displays for enhancing mental animation and improving reasoning in novice learning of probability," J. Comput. High. Educ., vol. 18, no. 1, pp. 55-79, Sep. 2006.

[25] F. Ke, H. Lin, and Y.-H. Ching, "Effects of animation on multi-level learning outcomes for learners with different characteristics: A meta-analytic assessment and interpretation," J. Vis. Lit., vol. 26, no. 1 , pp. 15-40, Aug. 2006.

[26] G. Ryle, Critical Essays. London: Hutchinson, 1949.

[27] R. M. Felder and L. K. Silverman, "Learning and teaching styles," J. Eng. Educ., vol. 78, no. 7, pp. 674-681, June. 1988.

[28] R. Dunn, "Understanding the dunn and dunn learning styles model and the need for individual diagnosis and prescription," J. Reading, Writ. Learn. Disabil. Int., vol. 6, no. 3, pp. 223-247, Sept. 1990.

[29] S. Graf, S. R. Viola, and T. Leo, "In-depth analysis of the felder-silverman learning style dimensions," J. Res. Technol. Educ., vol. 40, no. 1, pp. 79-93, Sep. 2007.

[30] R. M. Felder and B. A. Soloman, "Learning styles and strategies," 2004.

[31] G. Morrison, S. Ross, J. Kemp, and H. Kalman, Designing Effective Instruction, Hoboken, NJ: John Wiley \& Sons, Inc., 2011.
[32] W. Rothwell and H. Kazanas, Mastering the Instructional Design Process. A Systematic Approach, 4th Ed., San Francisco, CA: Pfeiffer, 2008.

[33] A. Baharin, M. Othman, S. S. M. Shafeq, and J. Haliza, "Kepelbagaian gaya pembelajaran dan kemahiran belajar pelajar universiti di Fakulti Pendidikan, UTM Johor," Skudai, 2007.

[34] E. M. Syahrizad and M. A. A. Zamzuri, "Survey on the challenges faced by the lecturers in using packet tracer simulation in computer networking course," Procedia Soc. Behav. Sci., vol. 131, pp. 11-15, May 2014.

[35] S. Kalyuga, "Managing cognitive load in adaptive ICT-based learning," J. Syst. Cybern. Informatics, vol. 7, no. 5, pp. 16-22, 2009.

[36] A. D. Baddeley, Working Memory, Oxford: Oxford University Press, 1986.

[37] J. Sweller, Instructional Design in Technical Areas, Camberwell, Australia: ACER Press, 1999.

[38] T. L. Naps, G. Rößling, V. Almstrum, W. Dann et al., "Exploring the role of visualization and engagement in computer science education," in Proc. Working Group Reports from ITiCSE on Innovation and Technology in Computer Science Education, 2002, pp. 131-152.

[39] T. L. Naps, "JHAVE - Addressing the need to support algorithm visualization with tools for active engagement," IEEE Comput. Graph. Appl., vol. 25, no. 5, pp. 1-15, 2005

[40] S. Kalyuga, "Prior knowledge principle in multimedia learning," in Cambridge Handbook of Multimedia Learning, R. E. Mayer, Ed., New York: Cambridge University Press, 2005, pp. 325-337.

[41] S. Kalyuga, "Expertise reversal effect and its implications for learner-tailored instruction," Educ. Psychol. Rev., vol. 19, pp. 509-539, Dec. 2007.

[42] S. Kalyuga, "Effects of learner prior knowledge and working memory limitations on multimedia learning," Procedia Soc. Behav. Sci., vol. 83, no. 1965 , pp. 25-29, Jul. 2013.

[43] R. M. Felder and J. Spurlin, "Applications , reliability and validity of the index of learning styles," Int. J. Eng. Educ., vol. 21, no. 1, pp 103-112, Jul. 2005.

[44] E. M. Syahrizad and M. N. Nizam, "Mengakaji gaya pembelajaran pelajar sebagai panduan pembinaan strategi pembelajaran," Persidangan Penyelidikan dan Inovasi (PePIN) 2013, 2013, pp. 375-383.

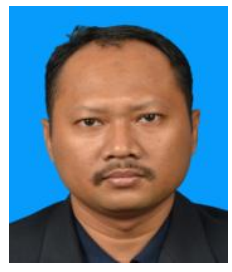

Mohd Syahrizad Elias is currently a PhD student in the Faculty of Art, Computing and Creative Industry, Universiti Pendidikan Sultan Idris, Malaysia. He has a $\mathrm{BSc}$ in electrical engineering from Universiti Teknologi Malaysia, and a MSc (information communication technology) from Universiti Utara Malaysia. His research interest is multimedia instructional message (MIM) and instructional technology.

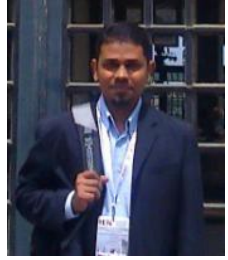

Ahmad Zamzuri Mohamad Ali is an associate professor of multimedia in the Faculty of Art, Computing and Creative Industry, Universiti Pendidikan Sultan Idris, Malaysia. He has a bachelor degree in electrical engineering from Universiti Teknologi Malaysia, a master in education from Universiti Teknologi Malaysia and a $\mathrm{PhD}$ in multimedia design from Universiti Sains Malaysia. He has taught both face-to-face and online classes in higher education for over 15 years. His research and publication interest is multimedia design, instructional technology, ICT in education and open source in education. 